\title{
The impact of helicobacter pylori eradication on platelet counts of adult patients with idiopathic thrombocytopenic purpura
}

Sara Aljarad ${ }^{1}$, Ahmad Alhamid ${ }^{3}$, Ahmad Sankari Tarabishi $^{3}$, Ameen Suliman $^{1}$ and Ziad Aljarad ${ }^{2 *}$ (1)

\begin{abstract}
Background: Idiopathic (immune) thrombocytopenic purpura (ITP) is an acquired disorder characterized by autoantibodies against platelet membrane antigens. Several studies found an association between Helicobacter Pylori infection and the incidence of ITP. So far, It is still unclear whether $H$. pylori eradication will increase platelet counts in adult ITP patients. We conduct this study to investigate platelet recovery in ITP patients after H. pylori eradication.

Methods: This is a prospective study. The diagnostic criterion for Idiopathic thrombocytopenic purpura is: isolated thrombocytopenia, with no evidence of any underlying causes like drugs, TTP, SLE, hepatitis, HIV,CLL and... etc. We examined blood smears of all patients. We have diagnosed Helicobacter pylori infection by histological examination of several biopsies obtained from stomach and duodenum by esophagogastroduodenoscopy (EGD). If EGD was not applicable due to patient's poor situation or platelet count, H.pylori infection was diagnosed by the positivity of serum antibodies or respiratory urease test. We treated infected patients with triple therapy (omeprazole $40 \mathrm{mg}$ once daily, amoxicillin $1000 \mathrm{mg}$ twice daily and clarithromycin $500 \mathrm{mg}$ twice daily) for 14 days. Uninfected patients did not receive any treatment. We did platelet quantification at the beginning of the study, at the end of the first month, at the end of the third month and at the end of the sixth month.

Results: This study involved 50 patients with chronic ITP, 29 males (58\%) and 21 females (42\%). Participants ages range between 18 and 51 years (mean age $=28.60$ years). We diagnosed H. pylori in 36 patients (72\%), who were treated with triple therapy. At the end of the sixth month, 10 of them (27.77\%) showed complete response, and 18 of them (50\%) showed partial response. The 14 uninfected patients, who did not receive any treatment, did not show neither complete nor partial response. Patient sex and age were not associated with achieving response, while baseline platelet count and H.pylori infection did.
\end{abstract}

Conclusion: Helicobacter pylori eradication significantly increases platelet counts in adult ITP patients.

Keywords: Idiopathic thrombocytopenic purpura, Helicobacter pylori, Platelet disorders

\footnotetext{
* Correspondence: dr.ziad-aljarad@hotmail.com

²Department of Gastroenterology, Aleppo University Hospital, Aleppo, Syria

Full list of author information is available at the end of the article
}

(c) The Author(s). 2018 Open Access This article is distributed under the terms of the Creative Commons Attribution 4.0 International License (http://creativecommons.org/licenses/by/4.0/), which permits unrestricted use, distribution, and reproduction in any medium, provided you give appropriate credit to the original author(s) and the source, provide a link to the Creative Commons license, and indicate if changes were made. The Creative Commons Public Domain Dedication waiver (http://creativecommons.org/publicdomain/zero/1.0/) applies to the data made available in this article, unless otherwise stated. 


\section{Background}

Idiopathic (immune) thrombocytopenic purpura (ITP) is an acquired disorder characterized by autoantibodies against platelet membrane antigens [1].

There are considerable differences in the clinical manifestations among ITP patients. The onset may be acute and sudden or may be insidious, and may result in significant mortality and morbidity. Patients may be asymptomatic, and symptoms in symptomatic patients range from easy bruising to severe bleeding [1].

Incidence rate of ITP is about 50-100 new cases per million per year, half of them are children. At least $70 \%$ of cases diagnosed in childhood will recover completely within six months, even without treatment $[2,3]$. A third of the remaining chronic cases will completely recover during follow-up [4, 5], another third will end up with only mild thrombocytopenia (platelet count above $50 \times 10^{9} / \mathrm{L}$ ) [6]

Thrombocytopenia Purpura is usually chronic in adults [7], and the probability of complete remission is 20-40. Male to female ratio in the adult group clearly differs in most age groups (children approximately have equal incidence in both sexes. The average age at diagnosis in adults is $56-60$ years [8].

Helicobacter pylori (H. pylori) is a gram-negative microaerophilic bacterium that colonizes in the stomach. H. pylori is implicated in the development of active chronic gastritis, gastric ulcers, and duodenal ulcers.

H. pylori is a cofactor in the development of both gastric adenocarcinoma and mucosa-associated lymphoid tissue lymphoma. Recently, It has been discovered that H. pylori is implicated in various autoimmune disorders, including pernicious anemia and idiopathic thrombocytopenic purpura (ITP) [9], linked to the development of peptic ulcers in stomach and gastric carcinoma. Approximately $50 \%$ of the world's population are infected with $H$. pylori, making it the most prevalent bacterial infections in the world. Its prevalence is greater in low-income countries than in developed ones [10]. The exact route of infection is still unknown, but fecal-oral and oral-oral routes seem to be the most likely [10].

No enough evidence is available to determine the impact of H.pylori eradication on platelet count in ITP patients. We also have not found in the medical literature a study in our region about the prevalence of $H$. pylori infection among ITP patients, and the effect of $H$. pylori eradication on ITP patients in our country, as related studies differ in their results from country to another. The objective of this research is to:

1. Determine the prevalence of $H$. pylori infection in ITP patients.

2. Evaluate the response of ITP patients to H. pylori eradication.

\section{Methods}

This prospective study was conducted at the University of Damascus, Division of Hematology at Al-Mouwasat University Hospital and Al Assad University HospitalDepartment of Internal Medicine, between October 2016 and October 2017. The study included all adult patients of both sexes, who were diagnosed with ITP according to the American Society of Hematology as follows:

- General platelet count is less than $100 \times 10^{9} / \mathrm{L}$.

- Exclusion of the secondary causes of thrombocytopenia (e.g. drugs, hepatitis $\mathrm{C}$ virus, Human Immunodeficiency virus, pseudothrombocytpenia, malignancies). We examined blood smears of all patients.

\section{Exclusion criteria}

- Patients younger than 14 years old.

- Patients with life-threatening bleeding or an active hemorrhage requiring immunosuppression or other therapeutic options to increase platelet count.

- Patients with secondary causes of thrombocytopenia, including any drugs that are suspected of developing thrombocytopenia.

- Taking antibiotics, proton pump inhibitors or $\mathrm{H} 2$ blockers a month before screening for H. pylori, because these lead to false negatives.

- Any previous $H$. pylori eradication program.

If platelet count and patient status allowed, We diagnosed H.pylori infection was by histological examination of different biopsies obtained from different areas of stomach and duodenum (including the gastric antrum) via esophagogastroduodenoscopy (EGD). IF EGD is not applicable, We diagnosed $H$. pylori infection by the positivity of serum antibodies or urease breath test. We first did serological testing. If the serology was positive, we considered the patient infected. If serology was negative, we did urease breath test. Infected patients were then given triple therapy for H.pylori (omeprazole $40 \mathrm{mg}$ once daily, amoxicillin $1000 \mathrm{mg}$ twice daily, clarithromycin $500 \mathrm{mg}$ twice daily) for 14 days. They were not given any additional ITP treatment to raise platelet count. Patients who were not infected with H.Pylori did not receive any treatment that aimed to increase platelet count during the follow-up period. This method helps to ensure that differences in outcomes are more likely to result from H.pylori eradication rather than other confounding treatments.

Patients had chronic ITP, which means that patients have taken several treatment lines like corticosteroids, splenectomy, IVIG and danazol before detecting HP but without. In addition, no life-threatening bleeding happened during the follow-up period. So, we did not give 
Table 1 Prevalence of infection with $\mathrm{H}$. Pylori and diagnostic methods used

\begin{tabular}{|c|c|c|}
\hline H.pylori infection: & Number of cases (\%): & Diagnostic method used: \\
\hline H. pylori positive $\left(\mathrm{Hp}^{+}\right)$Patients & $\begin{array}{l}36 \\
(72 \%)\end{array}$ & $\begin{array}{l}\text { - Positivity of serum antibodies or urease breath test in } 20 \text { patients ( } 55.56 \%) \text {. } \\
\text { - Histological examination of gastric and duodenal biopsies obtained by EGD } \\
\text { in } 16 \text { patients (44.44\%). }\end{array}$ \\
\hline H. Pylori negative $\left(\mathrm{Hp}^{-}\right)$Patients & $\begin{array}{l}14 \\
(28 \%)\end{array}$ & $\begin{array}{l}\text { - The Respiratory Urease test and serum antibodies in } 4 \text { patients }(28.5 \%) \text {. } \\
\text { - Histological examination of gastrointestinal lesions from the gastrointestinal } \\
\text { tract in } 10 \text { patients }(71.5 \%) \text {. }\end{array}$ \\
\hline
\end{tabular}

any therapeutic agent that may causes rising platelet count to avoid confounding differences in results between $\mathrm{Hp}$ positive and $\mathrm{Hp}$ negative patients.

Patients were followed up for 6 months. We did baseline platelet quantification, at the end of the first month, at the end of the third month and at the end of the sixth month.

No loss to follow-up or data missing happened.

\section{Response criteria}

As several similar studied did, We adopted the following definitions of response:

Complete response: Platelet count of more than $150 \times$ $10^{9} / \mathrm{L}$ (within the normal range).

Partial response: Elevation of Platelet count from $50 \times$ $10^{9} / \mathrm{L}$ to $50 \times 10^{9} / \mathrm{L}$, or twice the baseline platelet count.

\section{Statistical study}

We performed statistical analyses with SPSS (Version 22.0; SPSS Inc.: Chicago, IL, USA). We used P-value to evaluate statistical significance of differences between groups. The level of significance is $P<0.05$. Categorical variables were described using frequencies and percentages. Numerical variables were described using (mean or median standard deviation). In order to examine the significance of difference between groups, we conducted Chi-square test and Fisher exact test for categorical variables, and Student $\mathrm{T}$ test and the Mann-Whitney U test for numerical variables.

\section{Results}

The final sample of the study included 50 patients, 29 of them were males (58\%), and 21 were females (42\%). Participants ages were between 18 and 51 years (mean age $=28.60$ years), with a standard deviation of 8.75 years.

The prevalence of H.pylori infection was as following:

Thirty six patients $(72 \%)$ were diagnosed with $H$. pylori infection.

H. pylori infection was diagnosed by the positivity of both respiratory urease test or serum antibodies in 20 patients (55.56\%), and by histological examination of gastric and duodenal biopsies in 16 patients (44.44\%), as shown in (Table 1) and (Fig. 1).

\section{Platelet counts at the beginning of the study}

At the beginning of the study, platelet counts in $\mathrm{Hp}^{+}$ Patients ranged from $22 \times 10^{9} / \mathrm{L}$ to $88 \times 10^{9} / \mathrm{L}$, and the mean value was $46.25 \times 10^{9} / \mathrm{L} \quad(\mathrm{SD}=17.724)$. Platelet counts in $\mathrm{Hp}^{-}$Patients ranged from $12 \times 10^{9} / \mathrm{L}$ to $42 \times$ $10^{9} / \mathrm{L}$ and the mean value was $25.21 \times 10^{9} / \mathrm{L}(\mathrm{SD}=8.469)$. Independent sample $\mathrm{T}$ test shows that the mean platelet count of $\mathrm{Hp}^{-}$patients is significantly less than the mean platelet count of the $\mathrm{Hp}^{+}$Patients ( $\mathrm{P}(0.001)$. Table 2).

\section{Platelet counts at the end of the first month}

In $\mathrm{Hp}^{+}$patients, platelet counts ranged from $17 \times 10^{9} / \mathrm{L}$ to $215 \times 10^{9} / \mathrm{L}$, and the mean value was $67.94 \times 10^{9} / \mathrm{L}(\mathrm{SD}=$ 39.51). Platelet count increased in 23 patients $(63.88 \%)$ compared to baseline counts, and decreased in 13 patients (36.12\%). Only two patients (5.55\%) achieved complete response (platelet count $150 \times 10^{9} / \mathrm{L}$ ), and 10 patients (27.77\%) achieved partial response (platelet count elevation from to $50 \times 10^{9} / \mathrm{L}$, or twice the baseline platelet count). Overall response achieved in 12 patients (33.33\%).

In $\mathrm{Hp}^{-}$patients, platelet counts ranged from $21 \times 10^{9} / \mathrm{L}$ to $36 \times 10^{9} / \mathrm{L}$, and the mean value was $28.28 \times 10^{9} / \mathrm{L}$ (SD $=4.71$ ). Independent sample $\mathrm{T}$ test shows that the mean platelet count at the end of the first month of the study in $\mathrm{Hp}^{-}$patients is significantly less than the mean platelet count of the $\mathrm{Hp}^{+}$Patients (P (0.001) Table 2). Platelet count slightly increased in 6 patients $(42.85 \%)$, but they did not achieve neither complete nor partial response.

\section{Platelet counts at the end of the third month}

In $\mathrm{Hp}^{+}$patients, platelet counts ranged from $22 \times 10^{9} / \mathrm{L}$ to $357 \times 10^{9} / \mathrm{L}$, and the mean value was $112.13 \times 10^{9} / \mathrm{L}$ $(\mathrm{SD}=84.06)$. Platelet count increased in 27 patients

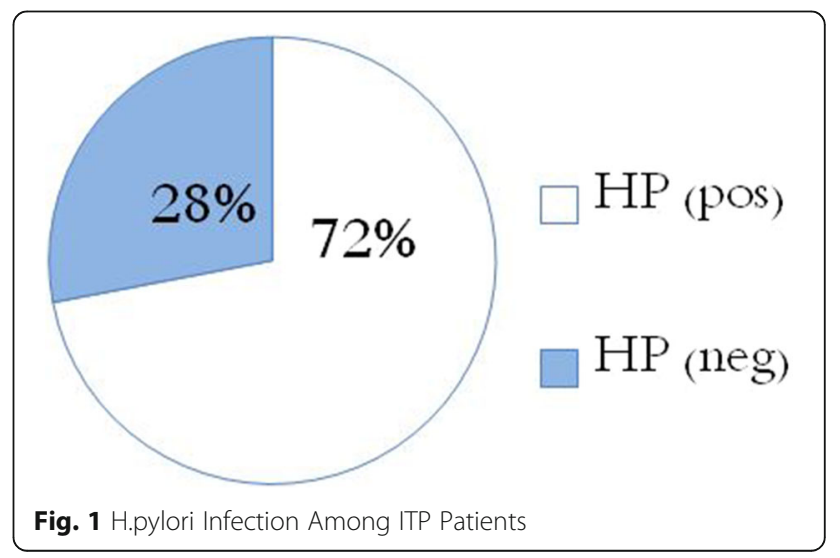


Table 2 Platelet Count during the study

\begin{tabular}{|c|c|c|c|c|c|}
\hline Groups & & $\begin{array}{l}\text { Range of platelet } \\
\text { counts }\left(10^{9} / \mathrm{L}\right)\end{array}$ & $\begin{array}{l}\text { The mean } \\
\text { value }\end{array}$ & $\begin{array}{l}\text { Standard } \\
\text { deviation }\end{array}$ & $P$ value \\
\hline \multirow[t]{2}{*}{ Platelet Count at the beginning of the study } & $\mathrm{HP}(+)$ & $22-88$ & 46.25 & 17.724 & \multirow[t]{2}{*}{0.001} \\
\hline & $\mathrm{HP}(-)$ & $12-42$ & 25.21 & 8.469 & \\
\hline \multirow[t]{2}{*}{ Platelet counts at the end of the first month } & $\mathrm{HP}(+)$ & $17-215$ & 67.94 & 39.51 & \multirow[t]{2}{*}{0.001} \\
\hline & $\mathrm{HP}(-)$ & $21-36$ & 28.28 & 4.71 & \\
\hline \multirow[t]{2}{*}{ Platelet counts at the end of the third month } & $\mathrm{HP}(+)$ & $22-357$ & 112.13 & 84.06 & \multirow[t]{2}{*}{0.001} \\
\hline & $\mathrm{HP}(-)$ & $15-42$ & 28.42 & 6.489 & \\
\hline \multirow[t]{2}{*}{ Platelet counts at the end of the sixth month: } & $\mathrm{HP}(+)$ & $15-212$ & 98.66 & 59.54 & \multirow[t]{2}{*}{0.001} \\
\hline & $\mathrm{HP}(-)$ & $15-41$ & 26.42 & 7.50 & \\
\hline \multirow{2}{*}{$\begin{array}{l}\text { difference in platelet counts between the end of } \\
\text { the sixth month and baseline platelet count } \\
\text { (platelet count at the end of the sixth month - baseline platelet count) }\end{array}$} & $\mathrm{HP}(+)$ & $(-37)-(187)$ & 52.42 & 37.66 & \multirow[t]{2}{*}{0.001} \\
\hline & $\mathrm{HP}(-)$ & $(-27)-(19)$ & 1.21 & 4.63 & \\
\hline
\end{tabular}

(75\%) compared to baseline counts, and decreased in 9 patients (25\%). 8 patients $(22.22 \%)$ achieved complete response, and 16 patients (44.44\%) achieved partial response. Overall response achieved in 26 patients (72.22\%).

In $\mathrm{Hp}^{-}$patients, platelet counts ranged from $15 \times 10^{9} /$ $\mathrm{L}$ to $42 \times 10^{9} / \mathrm{L}$, and the mean value was $28.42 \times 10^{9} / \mathrm{L}$ $(\mathrm{SD}=6.489)$. Independent sample $\mathrm{T}$ test shows that the mean platelet count at the end of the third month of the study in $\mathrm{Hp}^{-}$patients is significantly less than the mean platelet count of the $\mathrm{Hp}^{+}$Patients (P (0.001 Table 2)). Platelet count increased in 8 patients $(57.15 \%)$, but they did not achieve neither complete nor partial response.

\section{Platelet counts at the end of the sixth month}

In $\mathrm{Hp}^{+}$patients, platelet counts ranged from $25 \times 10^{9} / \mathrm{L}$ to $212 \times 10^{9} / \mathrm{L}$, and the mean value was $98.66 \times 10^{9} / \mathrm{L}(\mathrm{SD}=$ 59.54). Platelet count increased in 34 patients (94.44\%) compared to baseline counts, and decreased in two patients (5.56\%). 10 patients (27.77\%) achieved complete response, and 18 patients (50\%) achieved partial response. Overall response achieved in 28 patients $(77.77 \%)$.
In $\mathrm{Hp}^{-}$patients, platelet counts ranged from $15 \times 10^{9} / \mathrm{L}$ to $41 \times 10^{9} / \mathrm{L}$, and the mean value was $28.42 \times 10^{9} / \mathrm{L}$. Independent sample $\mathrm{T}$ test shows that the mean platelet count at the end of the sixth month of the study in $\mathrm{Hp}^{-}$patients is significantly less than the mean platelet count of the $\mathrm{Hp}^{+}$ Patients ( $\mathrm{P}(0.001)$ Table 2). Platelet count increased in 5 patients (25.71\%) compared to baseline, but they did not achieve neither complete nor partial response.

We notice a slight decrease in the mean platelet count of $\mathrm{Hp}^{+}$group at the end of the sixth month compared to that of the third month, so do the difference in means between $\mathrm{Hp}^{+}$and $\mathrm{Hp}^{-}$groups. But the mean platelet count of $\mathrm{Hp}^{+}$group at the end of the sixth month is still greater than that at the beginning of the study and at the end of the first month, so do the difference in means between $\mathrm{Hp}^{+}$and $\mathrm{Hp}^{-}$groups .

Mean platelet count in $\mathrm{Hp}^{+}$group at the end of the sixth month is still greater than the mean platelet count of $\mathrm{Hp}^{-}$ group at all stages. Furthermore, number of responding patients increased at the end of the sixth month.

Figure 2 shows the changes in mean platelet count in $\mathrm{Hp}^{+}$and $\mathrm{Hp}^{-}$groups.

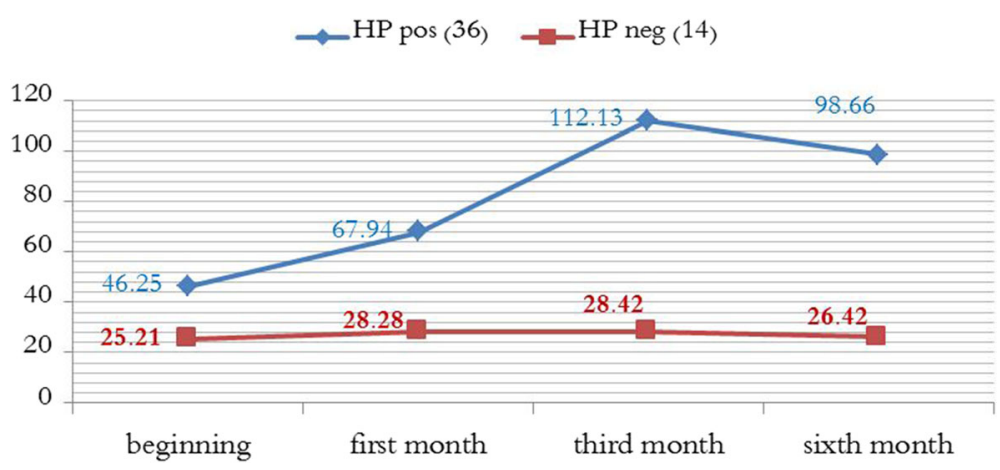

Fig. 2 The mean values of platelet counts in the two groups of H. pylori were changed during follow-up periods 


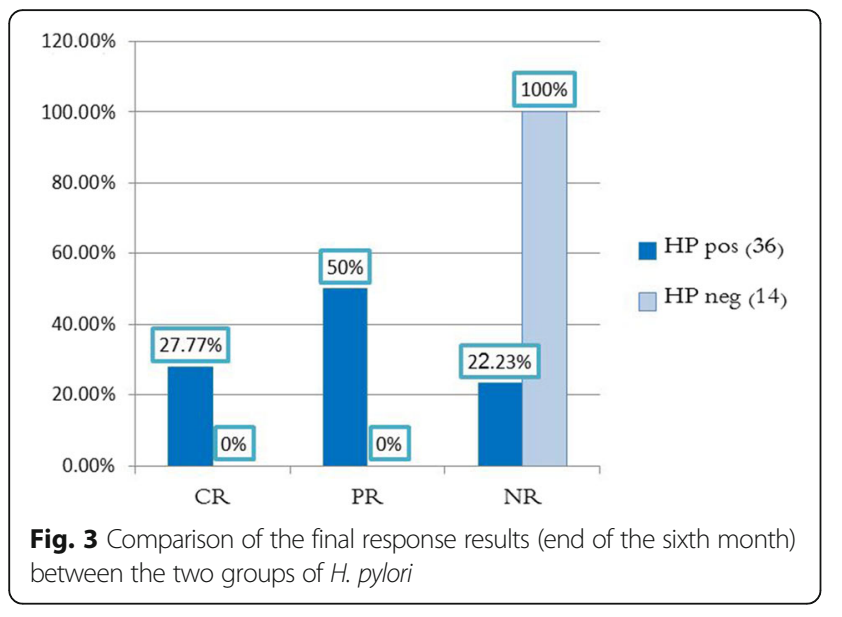

We conclude from Fig. 2 that: Although the mean baseline platelet count is greater in $\mathrm{Hp}^{+}$group, the difference between $\mathrm{Hp}^{+}$and $\mathrm{Hp}^{-}$groups is getting greater in the subsequent follow-up visits, as indicated by the gradually increased space between the curves. All that confirms the significant difference of platelet counts between the two groups (Table 2).

In conclusion, $10 \mathrm{Hp}^{+}$patients $(27.77 \%)$ achieved complete remission, and $18 \mathrm{Hp}^{+}$patients (50\%) achieved partial response. All responding patients are $\mathrm{Hp}^{+}$(who received triple therapy for H.pylori). $8 \mathrm{Hp}^{+}$ patients (22.23\%) achieved no response. All the 14 (100\%) Hp- patients (who received no treatment) did not achieve neither complete nor partial response (Fig. 3), even though some patients showed a slight increase in platelet count (Table 3). In other words, it is possible to say that treatment of $H$. pylori has effectively increased platelet count, and this improvement was not spontaneous.

\section{Comparison between complete response, partial response and no response groups}

After obtaining the final results of patients at the end of the sixth month, they were divided into three groups according to the response:

- Complete response group, including 10 patients.

- Partial response group, including 18 patients.

- No-response group, including 22 patients.

We will compare the three groups in terms of age distribution, sex distribution, baseline mean platelet count, H.pylori infection status.

\section{First: Comparison of the mean age}

The mean age of complete response group, partial response group, and no response group is 24.40, 28.95 years and 30.50 years, respectively as shown in (Fig. 4). One way ANOVA shows no statistically significant difference between these values. This means that age is not an effective factor in response Table 4.

\section{Second: Comparison of the primary platelet count}

The mean value of baseline platelet count in complete response group, partial response group and no response group is $40.50 \times 10^{9} / \mathrm{L}, 52 . \times 10^{9} / \mathrm{L}$ and $30.41 \times 10^{9} / \mathrm{L}$, respectively as shown in (Fig. 5). One way ANOVA test indicates a statistical significance of these differences as shown in (p) Table 4.

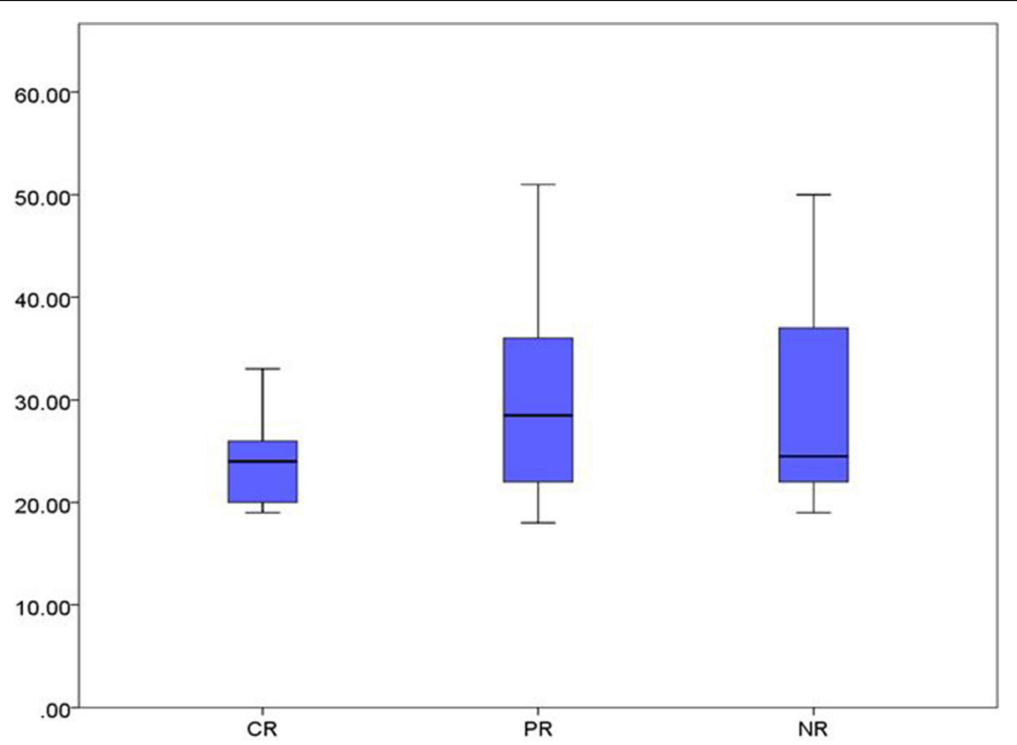

Fig. 4 Comparison of median age between complete response $C R$ and partial response PR and no- response NR 


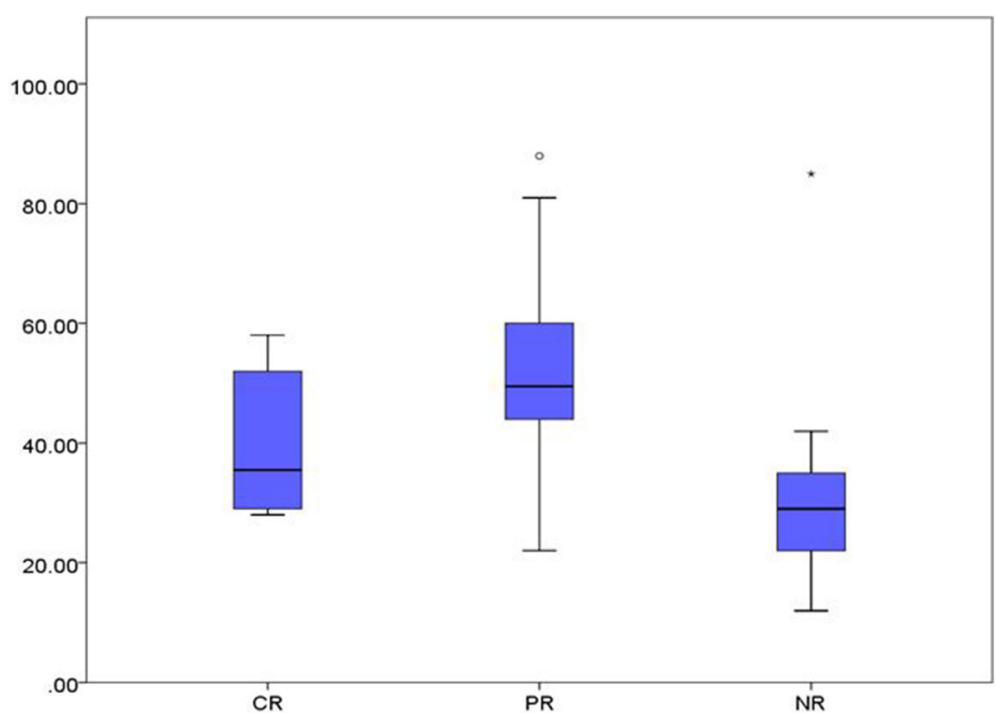

Fig. 5 Comparison of the median value of platelet count at the start of the study between complete response cases CR and partial response PR and non-response NR

\section{Third: Comparison of sex distribution}

The complete response group included 6 males (60\%) and 4 females (40\%). The partial response group included 9 males (50\%) and 9 females (50\%). No response group included 14 males (63.6\%) and 8 females (36.4\%) as shown in (Fig. 6). Fisher Exact test indicates that there is no statistically significant difference between these ratios. Therefore, patient's sex was not an effective factor to achieve response. As shown in Table 4.

\section{Fourth: Comparison of $H$. pylori infection status}

All cases of complete and partial response were $\mathrm{Hp}^{+}$. Out of the 22 cases of the no response group, 8 patients (36.4\%) were $\mathrm{Hp}^{+}$, and 14 patients (63.6\%) were $\mathrm{Hp}^{-}$as shown in (Fig. 7). Chi-square test indicates a statistically significant difference between these groups in H.pylori infection status. In other words, the response cases were more common among the HP (+) patients. That means $H$. pylori eradication increased platelet count, because no other treatment was given. As shown in Table 5.

\section{Discussion}

We gave Triple therapy to $\mathrm{Hp}^{+}$patients with no additional treatment, and $\mathrm{Hp}^{-}$were monitored without any treatment. Mean baseline platelet count was significantly higher in

Table 3 Comparison of the end result of the response (end of the sixth month) between the two groups of $\mathrm{H}$. Pylori

\begin{tabular}{llll}
\hline & $\mathrm{HP}(+)(36)$ & $\mathrm{HP}(-)(14)$ & $P$ value \\
\hline Complete response & $10(27.77 \%)$ & $0(0 \%)$ & \\
Partial response & $18(50 \%)$ & $0(0 \%)$ & 0.001 \\
No response & $8(22.23 \%)$ & $14(100 \%)$ & 0.001 \\
\hline
\end{tabular}

$\mathrm{Hp}^{+}$group. Mean platelet count of $\mathrm{Hp}^{+}$patients was also significantly higher than that of $\mathrm{Hp}^{-}$at the end of the first, third and sixth month. Mean platelet count markedly improved in $\mathrm{Hp}^{+}$group, and the difference in mean platelet count was gradually getting greater in subsequent followup visits at the end of the first month and third month.

We notice a slight decrease in the mean platelet count of $\mathrm{Hp}^{+}$group at the end of the sixth month compared to that of the third month, so do the difference in means between $\mathrm{Hp}^{+}$and $\mathrm{Hp}^{-}$groups. But the mean platelet count of $\mathrm{Hp}^{+}$group at the end of the sixth month is still greater than that at the beginning of the study and at the end of the first month, so do the difference in means between $\mathrm{Hp}^{+}$and $\mathrm{Hp}^{-}$ groups. Mean platelet count in $\mathrm{Hp}^{+}$group at the end of the sixth month is still greater than the mean platelet count of $\mathrm{Hp}^{-}$group at all stages.

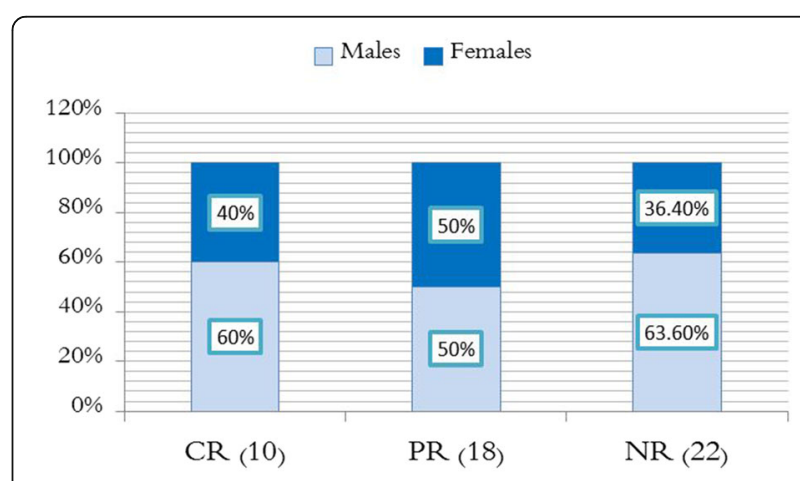

Fig. 6 Comparison of sex distribution between complete response $C R$ and partial response PR and non-response NR 
Table 4 Comparison of the platelet count, and the patient's sex, and the median age, by type of response

\begin{tabular}{llcccc}
\hline & & Platelet count & Males & Females & $\begin{array}{l}\text { Median } \\
\text { age }\end{array}$ \\
\hline $\begin{array}{l}\text { Complete } \\
\text { response }\end{array}$ & $\mathrm{HP}(+)(36)$ & 40.50 & $6(60 \%)$ & $4(40 \%)$ & 24.40 \\
Partial & $\mathrm{HP}(-)(14)$ & & & & \\
response & $\mathrm{HP}(-)(16)$ & 52.44 & $9(50 \%)$ & $9(50 \%)$ & 28.95 \\
No & $\mathrm{HP}(+)(36)$ & 30.41 & $14(63.6 \%)$ & $8(36.4 \%)$ & 30.50 \\
response & $\mathrm{HP}(-)(14)$ & & & & \\
\hline
\end{tabular}

The difference between mean baseline platelet count and mean platelet count at the end of the sixth month was significantly higher in $\mathrm{Hp}^{+}$group.

Patients who achieved complete or partial response were all $\mathrm{Hp}^{+}$, while $\mathrm{Hp}^{-}$patients did not achieve neither complete nor partial response. The previous findings indicate that the improvement noticed in $\mathrm{Hp}^{+}$group is often due to H.pylri eradication, not a spontaneous improvement.

Age and sex are not related to achieving response, while baseline platelet count and H.pylori infection status do.

\section{Scientific explanation of this improvement}

The pathogenic role of $H$. pylori infection in the development of ITP is still unclear, several mechanisms are suggested: $H$. pylori may modify the balance of Fc-receptors on the surface of monocytes. This modification leads to activation of these receptors, which makes monocytes attack platelets. Bacterial antigens and glycoprotein platelet surface antigens express some similarity. When antibodies are produced against these bacterial antigens, they interact with the glycoprotein Platelet surface antigens, thus lead to decrease platelet count. Some strains of $H$. pylori induce platelet activation mediated

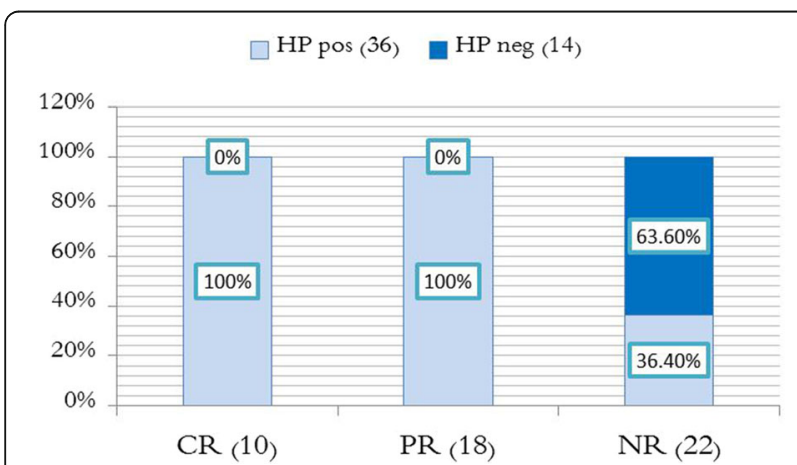

Fig. 7 Comparison of the percentages of the H. pylori infection with complete response CR and partial response PR and non-response NR
Table 5 Comparison the percentages of the H. Pylori infection by type of response

\begin{tabular}{llll}
\hline Group & HP (+) (36) & HP (-) (14) & $P$ value \\
\hline Complete response(10) & $10(100 \%)$ & $0(0 \%)$ & Less than 0.001 \\
Partial response (18) & $18(100 \%)$ & $0(0 \%)$ & \\
No-response (22) & $8(36.4 \%)$ & $14(63.6)$ & \\
\hline
\end{tabular}

by $H$. pylori-bound vWF interacting with GPIb, and supported by IgG. [11-15].

Study limitations include the small sample size due to the rarity of ITP. Another limitation is the absence of a control group consisted of healthy asymptomatic participants to compare the prevalence of H.pylori infection between ITP patients and the healthy population.

\section{Conclusion}

- H. pylori eradication in ITP patients Leads to significant Improvement of peripheral blood platelet count in most patients.

\section{Recommendations}

- To investigate for $H$. pylori infection in ITP patients, even in the absence of gastrointestinal symptoms.

- To consider the triple anti-H.pylori therapy as a first therapeutic option for $\mathrm{Hp}^{+}$ITP patients, with periodic monthly monitoring of platelet count during the first 6 months to confirm the response.

- To conduct a large-scale well-controlled casecontrol studies to confirm the relationship between H.pylori infection and the development of ITP.

- To conduct randomized controlled trials to confirm the benefit of $\mathrm{H}$.pylori eradication in $\mathrm{Hp}^{+}$ITP patients.

- To conduct a systematic review and meta-analysis of the available literature.

\section{Abbreviations}

H. pylori: Helicobacter pylori; HCV: hepatitis C virus; HIV: human immunodeficiency virus; HP: Helicobacter pylori; ITP: Idiopathic Thrombocytopenic Purpura; IMG: Intravenous immunoglobulin; SLE: Systemic lupus erythematous; SPSS: a statistical package for the social sciences; TTP: thrombotic thrombocytopenic purpura

Availability of data and materials

The data sets used and/or analyzed during the current study are available from the corresponding author on reasonable request.

\section{Author's contribution}

Conception and design: ZA, AST, AA.Analysis and interpretation of the data: ZA, SA, AS.Drafting of the article: ZA, SA, AST, AA.Critical revision of the article for important intellectual content: SA, AS. All authors read and approved the final version of the manuscript.

\section{Ethics approval and consent to participate}

The study was approved by the Ethics Committee who supervised the study, Prof. Ameen Suliman, Head of Hematology, Al Mouwasat University Hospital, Damascus, Syria.And Prof. Abir Kaddar, Head of Hematology, Al Assad University Hospital, Damascus, Syria.Verbal consent was obtained from 
participants and the ethics committee approved the verbal consent. Verbal consent was obtained because the study was conducted at Al Mouwasat University Hospital and Al Assad University Hospital, which are university hospitals, so people who come to these hospitals know that their data may be used for doing research.

\section{Consent for publication}

Not applicable.

\section{Competing interests}

The authors declare that they have no competing interest.

\section{Publisher's Note}

Springer Nature remains neutral with regard to jurisdictional claims in published maps and institutional affiliations.

\section{Author details}

'Department of Hematology, Al Mouwasat University Hospital, Damascus, Syria. ${ }^{2}$ Department of Gastroenterology, Aleppo University Hospital, Aleppo, Syria. ${ }^{3}$ Medical student, Faculty of Medicine, University of Aleppo, Aleppo, Syria.

Received: 16 February 2018 Accepted: 31 August 2018

\section{Published online: 20 September 2018}

\section{References}

1. Terrell $D R$, Beebe $L A$, Neas $B R$, et al. Prevalence of primary immune thrombocytopenia in Oklahoma. Am J Hematol. 2012 Sep;87(9):848-52.

2. Rodeghiero F, Stasi R, Gernsheimer T, et al. Standardization of terminology, definitions and outcome criteria in immune thrombocytopenic purpura of adults and children. Report from an international working group. Blood. 2009 Mar 12;113(11):2386-93.

3. Kuhne T, Imbach P, Bolton Maggs PH, et al. Newly diagnosed ITP in the children an observational study. Lancet. 2001;358(9299):2122-5.

4. Toltl LJ, Arnold DM. Pathophysiology and management of chronic immune thrombocytopenia: focusing on what matters. Br J Haematol. 2011 Jan; 152(1):52-60.

5. Franchini M, Veneri D. Helicobacter pylori -associated immune thrombocytopenia. Am J Hematology. 2012 Jul;38(5):463-8.

6. Neunert C, Lim W, Crowther M, et al. The American Society of Hematology 2011 evidence-based practice guideline for immune thrombocytopenia. Blood. 2011 Apr 21;117(16):4190-207.

7. Cines DB. Blanchette . "immune thrombocytopenic purpura". N Engl J Med. 2002:346(13):995-1008.

8. Cines DB, Bussel JB (2005). how I treat idiopathic thrombocytopenic purpura (ITP). Blood 2012:120(5):960-969.

9. Tan HJ, Goh KL. Extragastrointestinal manifestations of helicobacter pylori infection: facts or myth? A critical review. J Dig Dis. 2012 Jul:13(7):342-9.

10. Weiss AA. Helicobacter pylori treatment and eradication. In: Sands MD BE, editor. "MOUNT SINAI EXPERT GUIDES gastroenterology" textbook. 1st ed: 2015. p. 180-93.

11. Campuzano-Maya G. Proof of an association between helicobacter pylori and idiopathic thrombocytopenic purpura in Latin America. Helicobacter. 2007 Jun;12(3):265-73.

12. Gerhard M, Rad R, Prinz C, Naumann M. Pathogenesis of helicobacter pylori infection. Helicobacter. 2002;7(Suppl 1):17-23.

13. Cines DB. ITP: time to "bug off"? Blood. 2007;110(12):3818-9.

14. Byrne MF, Kerrigan SW, Corcoran PA, et al. Helicobacter pylori binds von Willebrand factor and interacts with GPIb to induce platelet aggregation Gastroenterology. 2003 Jun;124(7):1846-54.

15. Stasi R, Rossi Z, Stipa E, Amadori S, Newland AC, Provan D. Helicobacter pylori eradication in the management of patients with idiopathic thrombocytopenic purpura. Am J Med. 2005 April;118(4):414-9.

\section{Ready to submit your research? Choose BMC and benefit from:}

- fast, convenient online submission

- thorough peer review by experienced researchers in your field

- rapid publication on acceptance

- support for research data, including large and complex data types

- gold Open Access which fosters wider collaboration and increased citations

- maximum visibility for your research: over $100 \mathrm{M}$ website views per year

At $\mathrm{BMC}$, research is always in progress.

Learn more biomedcentral.com/submissions 